\title{
Etnohistoria y política educativa. Repensando el sujeto y las fuentes en la reforma educativa republicana en España (1931-1936)*
}

Juan Alfredo Jiménez Eguizábal

Afiliado institucionalmente con la Universidad de Burgos (España).Correo electrónico: ajea@ubu. es. El autor es doctor en Filosofía y Ciencias de la Educación de la institución en mención. Entre sus publicaciones recientes tenemos: "Ocio, política y educación. Reflexiones y retos veinticinco siglos después de Aristóteles”, Revista Española de Pedagogía No. 73 (2015). Entre sus temas de interés están Historia de la política educativa, Política curricular, Emprendimiento.

\section{Carmen Palmero Cámara}

Afiliada institucionalmente con la Universidad de Burgos (España).Correo electrónico: cpalmero@ ubu.es. La autora es doctora en Filosofía y Ciencias de la Educación de la institución en mención. Entre sus publicaciones recientes tenemos: en coautoría "La figura del profesor como agente de cambio en la configuración de la competencia emprendedora", Revista Interuniversitaria de Formación del Profesorado 86 (30.2) (2016). Entre sus temas de interés están Historia de la Política Educativa, Educación Comparada.

Recibido: 24 de octubre de 2017

Aprobado: 13 de marzo de 2018

Modificado: 22 de marzo de 2018

Artículo de investigación científica

DOI: http://dx.doi.org/10.15648/hc.33.2018.9

* $\quad$ Este artículo forma parte del proyecto: "De los tiempos educativos a los tiempos sociales: Impacto de la educación en la red de emprendimiento en los jóvenes. Competencias e innovaciones curriculares (Referencia EDU 2012-39080-C07-06)" financiado por Ministerio de Economía y Competitividad a través del Plan Nacional de I+D+I (2012-2015) (España).

Esta publicación está bajo una licencia Creative Commons Reconocimiento-NoComercial 4.0 
Etnohistoria y política educativa. Repensando el sujeto y las fuentes en la reforma educativa republicana en España (1931-1936)

\title{
Resumen
}

La historia de la política educativa, al igual que otras historias especializadas, ha experimentado distintos cambios historiográficos como reacción a los modos en que los historiadores han ido percibiendo la crisis epistemológica de las ciencias sociales. En este contexto de cambio, el artículo como primer objetivo trata de mostrar el potencial innovador y la fecundidad heurística que aporta la rehabilitación de lo cotidiano, el retorno a una filosofía del sujeto y la utilización de fuentes etnográficas para explicar las estructuras y funcionalidad del poder, identificando los paralelismos y divergencias entre la lógica de los discursos y el sentido de las prácticas en la historia de la política educativa. Actitudes epistemológicas que se aplican al estudio de la reforma educativa republicana en España, asumiendo como segundo objetivo desvelar que las cuestiones controvertidas y disputadas de la política educativa de esta época son susceptibles de historiarse de forma más solvente a partir de las miradas cruzadas que nos proporcionan los recuerdos y olvidos de sus actores, el recurso a la oralidad y, en general, la investigación etnográfica.

Palabras clave: historia de la educación, política educativa, epistemología, etnografía, oralidad, reforma educativa republicana en España.

\section{Ethnohistory and educational policy. Rethinking the subject and the sources in the republican educational reform in Spain (1931-1936)}

\begin{abstract}
The history of educational policy, like other specialized ones, has experienced different historiographical changes in response to the ways in which historians have been perceiving the epistemological crisis of the Social Sciences. In this changing context, our first objective is to show the innovative potential and the heuristic fruitfulness that rehabilitation of everyday life offers, the return to a philosophy of the subject and the use of ethnographic sources to explain the structure and functionality of power by identifying the similarities and divergences between the logic of the speeches and the sense of practices in the history of educational policy. These epistemological attitudes are applied to the study of the republican educational reform in Spain. Our second objective is to reveal that the controversial and disputed issues of the educational policy
\end{abstract}


of this period are susceptible of being depicted in a better way from diverse perspective provided by the memories and omissions of its actors, the orality, and in general, the ethnographic research.

Key words: history of education, educational policy, epistemology, ethnography, orality, republican educational reform in Spain.

\section{Etnohistoria e política educativa. Repensando o sujeito e as fontes na reforma educativa republicana em Espanha (1931-1936)}

\section{Resumo}

A história da política educativa, ao igual que outras histórias especializadas, tem experimentado diferentes mudanças historiográficos como reacção aos modos em que os historiadores têm ido percebendo a crise epistemológica das ciências sociais. Neste contexto de mudança, o artigo como primeiro objectivo trata de mostrar o potencial inovador e a fecundidad heurística que contribui a reabilitação do quotidiano, a volta a uma filosofia do sujeito e a utilização de fontes etnográficas para explicar as estruturas e funcionalidade do poder, identificando osparalelismos e divergências entre a lógica dos discursos e o sentido das práticas na história da política educativa. Atitudes epistemológicas que se aplicam ao estudo da reforma educativa republicana em Espanha, assumindo como segundo objectivo desvelar que as questões controvertidas e disputadas da política educativa desta época são susceptíveis de historiarse de forma mais solvente a partir das miradas cruzadas que nos proporcionam as lembranças e esquecimentos de seus actores, o recurso à oralidad e, em general, a investigação etnográfica.

Palavras-chave: história da educação, política educativa, epistemología, etnografía, oralidad, reforma educativa republicana em Espanha.

L'ethnohistoire et la politique éducative. Á repenser le sujet et les sources de la réforme de l'éducation républicaine en Espagne (1931-1936)

\section{Résumé}

Comme d'autres types d'histoires spécialisées, l'histoire de la politique éducative a connu différents changements au niveau historiographique en réponse aux façons dont les historiens ont entendu la crise épistémologique des sciences sociales. Dans ce contexte de changement, cet article a pour but principal de révéler le potentiel d'innovation et 
la fécondité heuristique, laquelle favorise premièrement, la réhabilitation de ce qui est quotidien, et en deuxième lieu, elle incite à la philosophie du sujet et l'utilisation des sources ethnographiques expliquant les structures et la fonctionnalité du pouvoir. Il est ainsi qu'il est possible d'identifier les parallélismes et les divergences entre la logique des discours et le sens des pratiques historiques de la politique éducative. Ces conduites épistémologiques appliquées à l'étude de la réforme éducative républicaine en Espagne permettent d'approuver comme deuxième objectif de cet article, que les questions controversées et disputées de la politique éducative de cette époque, sont susceptibles d'être racontées d'une manière plus efficace, cela à partir des regards croisées pourvues par les souvenirs et les oublis de leurs acteurs, ainsi que le recours à l'oralité et en général, à la recherche ethnographique.

Mots clés: histoire de l'éducation, politique éducative, épistémologie, ethographie, oralité, réforme éducative républicaine en Espagne.

"Mas cada cual el rumbo siguió de su locura; agilizó su brazo, acreditó su brío; dejó como un espejo bruñida su armadura y dijo: El hoy es malo, pero el mañana....es mío". Antonio Machado. Campos de Castilla (CXLIV)

\section{INTRODUCCIÓN}

La arquitectura de un número monográfico de revista ordenado a renovar la construcción historiográfica de la educación en el siglo XX, y cuya razonada causa final es el intento de exponer las miradas cruzadas que nos ayudan a identificar y explicar las interacciones y transformaciones operadas en este interesante período de la historia sociocultural y educativa, legítimamente puede dar cabida, entre sus contribuciones, a la historia de la política educativa como atalaya privilegiada para el registro y explicación, en el contexto más realista y amplio, de evidencias, prácticas y modos empíricos de producción de poder ${ }^{1}$.

1 Una aproximación conceptual y metodológica a la nueva historia política de la educación que focaliza las relaciones de poder y sus interacciones con la historia de la política educativa puede verse, entre 
El presente artículo se plantea como primer objetivo mostrar los efectos positivos inducidos en la historia de la política educativa a través de la incorporación de metodologías etnográficas, fundamentalmente centradas en el sujeto y en la ampliación de fuentes, poniendo de manifiesto el interés en estudiar cómo los actores crean, construyen y ejercen poder para reconstruir los significados del pasado más inmediato ${ }^{2}$. Dar voz y participación a los protagonistas, registrar sus percepciones y vivencias, aprender a ver justo allí donde parecía que no había nada que ver, es dar paso a una mirada que, convenientemente triangulada con la literatura científica y los materiales archivísticos, proporciona la perspectiva adecuada para construir el marco interpretativo general y las hipótesis explicativas de los hechos, discursos y prácticas pedagógicas implementadas en la educación del siglo $\mathrm{XX}^{3}$. En esta línea, se someten también a revisión las repercusiones que esta renovación metodológica ha comportado en las principales y más reconocidas líneas de investigación empírica de la política educativa.

Pero, en todo caso, la comprensión cabal y refinada del nuevo modo de hacer historia de la política educativa sólo puede cobrar cuerpo en un ejercicio de construcción de la historiografía pedagógico-política sobre escolarización y sociedad. Por ello, como segundo gran objetivo, se aborda -provistos de la mirada original del sujeto y prestando atención a la ampliación de fuentes- la historia de la política educativa republicana en la España de 1931 a 1936, como una de las variables más influyentes y decisivas en la evolución del pensamiento pedagógico y en el proceso de escolarización, y a la vez como uno de los medios de acceso privilegiados a la situación, avances e inflexiones de la práctica escolar.

otros, en Juan Manuel Fernández Soria, "La nueva historia política de la educación", Historia de la Educación 25 (2006):71-103; Manuel de Puelles Benítez, Política educativa en perspectiva histórica (Madrid: Biblioteca Nueva, 2017).

2 Veánse, entre otros: Cristina Yanes-Cabrera, Juri Meda y Antonio Viñao (Eds.), School Memories. New Trends in the History of Education (Switzerland: Springer International Publishing, 2016); Manuel Ferraz (Ed.), Repensar la historia de la Educación. Nuevos desafíos, nuevas propuestas, (Madrid: Biblioteca Nueva, 2006).

3 Véanse, entre otros: María del Mar del Pozo Andrés, "Imágenes e historia de la educación: construcción, reconstrucción y representación de las prácticas escolares en el aula”, Historia de la Educación, 25 (2006): 291-315; Antonio Viñao Frago, "La memoria escolar: restos y huellas, recuerdos y olvidos", Annali di Storia dell'Educazione e dell Istittuzione Scholastiche, 12 (2005):19-33. 


\section{LA CONSIDERACIÓN DEL ACTOR}

La historia de la educación, al igual que otras historias especializadas, ha experimentado distintos cambios historiográficos surgidos en buena parte como reacción a los modos en que los historiadores han ido percibiendo la crisis epistemológica de las Ciencias Sociales. En el trasfondo de estos impulsos, durante las últimas décadas se han producido, junto a la aparición de nuevos campos historiográficos, cambios sustanciales en el enfoque y la forma de concebir la disciplina, tanto en sus paradigmas científicos como en sus criterios académicos, certeramente identificados y analizados en rigurosos trabajos publicados a finales del siglo XX y dedicados a roturar los nuevos perfiles de la historia general y educativa ${ }^{4}$.

En esta desafiante y, en cierto modo, disruptiva tendencia epistemológica, uno de los obstáculos más controvertidos que han tenido que solventar los historiadores ha sido el de la localización, organización, manejo y evaluación de las fuentes pertinentes, que asegure tanto su autenticidad, como su veracidad y significación. Aspectos sobre los que ya en 1984, con cierta prognosis, el profesor Escolano sistematizaba el interesante debate provocado por las tendencias historiográficas en torno a la ampliación del concepto de fuente, así como sobre la extensión del perfil y competencias de la actividad investigadora ${ }^{5}$.

En este nuevo mapa de situación, parece una tesis suficientemente contrastada que la historia de la educación en su constante propósito de desvelar campos de investigación relevantes ha atinado admirablemente a

4 Véanse las fundamentadas propuestas de: Marc Léopold Benjamin Bloch, Introducción a la historia (México: FCE, 1985); David Crook and Richard Aldrich, History of Education for the Twenty-First Century (London: Institute of Education, 2000); Lucien Febvre, Combates por la Historia (Barcelona: Ariel, 1974); Jacques Le Goff y Pierre Nora, Hacer la historia. I. Nuevos problemas, II. Nuevos enfoques, III. Nuevos temas (Barcelona: Laia, 1978-1980); Antonio Nóvoa, "La nouvelle histoire américain de l'éducation”, Histoire de l'éducation 73 (1997); Antonio Nóvoa y Julio Ruiz Berrio (Eds.), A História da Educaçao em Espanha e Portugal. Investigaçoes e actividades (Lisboa: Sociedade Portuguesa de Ciências da Educaçao-Sociedad Española de Historia de la Educación, 1993); Kadriya Salimova and Erwin V. Johanningmeir (Eds.), Why should we teach history of education? (Moscow: The Library of International Academy of Self-Imporvement, 1993).

5 Agustín Escolano, "Introducción”, en Diccionario de Ciencias de la Educación. Tomo de Historia de la Educación I (Madrid: Anaya, 1984), IX-XLIII. 
centrar la atención en la denominada rehabilitación de lo cotidiano ${ }^{6}$. En las circunstancias actuales, ya no se descuida el significado del actor educativo y de su praxis diaria, sus vivencias, relaciones y conflictos con otros actores, así como su papel decisivo en la configuración institucional del poder, enriqueciéndose notablemente la amplitud y diversidad del objeto histórico. Y prestando atención a las señales que guarda y emite el sujeto pueden comprenderse mejor las significaciones y orientaciones generales de la política educativa, el modo en que las decisiones políticas llegan y son aplicadas por sus receptores, proporcionando acercamiento crítico e impulso metódico para plasmar los paralelismos y las incoherencias entre la lógica de los discursos y de las prácticas. En esta línea, cobra sentido el método de trabajo etnográfico que valora la oralidad de los actores -testimonios directos de quienes participaron en el desarrollo de un proceso histórico-, cuya palabra y testimonios emergen como fuente esencial para la construcción, razonablemente creativa y solvente, de la historia reciente de la política educativa ${ }^{7}$. Además, el retorno de la atención al sujeto en la metodología histórica rehabilita la parte explícita y reflexiva de la acción humana generando una revalorización de lo político por considerarlo como el nivel más abarcador y comprensivo de la organización y funcionamiento social ${ }^{8}$.

Los efectos y el potencial innovador de estas tendencias nos coloca en la tesitura de romper con fórmulas y esquemas convencionales con los que se ha venido cultivando la historia de la política educativa -no siempre suficientemente elástica para objetivar los fenómenos relacionados con el

6 Agustin Escolano, "Ethnohistory of the School. Representations of Modernity", Sisyphus. Journal of Education 4, 1 (2016): 12-41.

7 Véanse: Jorge Eduardo Aceves, "La historia oral y de vida: del recurso técnico a la experiencia de investigación", en Técnicas de investigación en sociedad, cultura y comunicación, ed. Luis Jesús Galindo (México: Pearson, 1998), 207-276; Julio Ruiz Berrio, "El método histórico en la investigación histórico-educativa", en La investigación histórico-educativa, ed. Narciso de Gabriel y Antonio Viñao (Barcelona: Ronsel, 1997), 131-202; Pilar Folguera, Cómo se hace historia oral (Madrid: Eudema,1994); Linda Shopes, "Diseño de proyectos de historia oral y formas de entrevistar", Revista Historia y Fuente Oral, 25 (2001): 133-141.

8 Véanse, entre otros: Fernando Cabral Pinto (coord.), Educaçao, História e Políticas. Tributo a Rogério Eernandes (Lisboa: Ediçôes Piaget, 2015); Isabel Morant, "Introducción”, en Escribir las prácticas: discurso, práctica, representación, ed. Roger Chartier (Valencia: Fundación Cañada Blanch, 1999). 
poder-y nos conduce a sugerir que las grandes cuestiones más disputadas y controvertidas de la política educativa reciente son susceptibles de historiarse con un tratamiento ventajoso desde el recurso a la dimensión creativa de la oralidad y a procesos de investigación etnográficos vinculados a los recuerdos, silencios y olvidos de los actores del sistema educativo? Orientación que, además de potenciar la discusión y la labor crítica en la explicación histórica, cumple con el objetivo que se le plantea a todo investigador de impulsar la ampliación del universo de fuentes como materia prima de la producción historiográfica.

\section{El desafío de Historiar EL PODER}

No resulta exagerado afirmar que la práctica totalidad de los conflictos actuales, sobre los que la política educativa debe explicar y normativizar el curso de su acción práctica, manifiestan una evidente carga de historicidad, tal y como patentizan de forma ejemplar los rigurosos estudios históricos de política educativa de Marc Depaepe ${ }^{10}$, Alejandro Mayordomo ${ }^{11}$ y Antonio Viñao ${ }^{12}$, demostrando hasta qué punto el hecho político-educativo se encuentra sometido al cambio histórico. De forma paralela, en el ámbito de la ciencia política en general politólogos contrastados como Skocpol ${ }^{13}$, Flora y Heidenheimer ${ }^{14}$ y Fernández-Carvajal ${ }^{15}$, han mostrado con acierto el valor correctivo de la historia para interpretar la realidad política.

Además, cuando esta acertada interacción de la historia y la política edu-

9 Daniel Bertaux, Los relatos de vida. Perspectiva etnosociológica (Barcelona: Ediciones Bellaterra, 2005).

10 Marc Depaepe, «L'apport de l'histoire de l'éducation a la définition des politiques éducatives. Quelques réflexions méthodologiques», en L'offre de l'école (París: Publications de la Sorbonne-INRP, 1983).

11 Alejandro Mayordomo, Perspectivas de la política educativa española (Valencia: Universidad de Valencia, 1985).

12 Antonio Viñao, Política y educación en los orígenes de la España contemporánea. Examen especial de sus relaciones en la enseñanza secundaria (Madrid: Siglo XXI, 1982).

13 Theda Skocpol, "Bringing the State back in: strategies of analysis in current research", en. Bringing the State Back In, eds. Peter Evans, Dietrich Rueschemeyer y Theda Skocpol (Cambridge: Cambridge University Press, 1985).

14 Peter Flora and Arnold Heidenheimer (Eds.), The development of welfare state in Europe and in America (New Brunswick: Transaction Books, 1981).

15 Rodrigo Fernández-Carvajal, El lugar de la ciencia política (Murcia: Universidad de Murcia, 1981). 
cativa se focaliza sobre coyunturas recientes, el recurso a la oralidad del sujeto de la acción política, a su testimonio y, en general, al diseño etnográfico $^{16}$, aporta nuevas dimensiones para la comprensión del contenido de las normas y declaraciones de carácter político-administrativo, así como de los mecanismos y prácticas más significativas de la política, que exhiben contenidos e imágenes plurales, versátiles y permanentemente mutables; rasgos que han influido poderosamente en el complejo proceso de construcción de la política como ciencia social independiente.

De este modo, los recuerdos, también los silencios, del sujeto objetivan un mundo narrado que propicia encontrar un punto de equilibrio entre la teoría y la praxis al historiar el poder. Relatos que convenientemente sometidos a crítica nos permiten, no solo construir teorías idiográficas que explican casos concretos, sino también a partir de los testimonios que nos merecen credibilidad elaborar teorías nomotéticas que forman parte de una tradición compartida ${ }^{17}$, superando, de este modo, tanto el denominado hiperfactualismo peculiar del funcionamiento político en Estados Unidos, como el normativismo, especialmente jurídico, propio de la administración europea.

En estas condiciones, historiar la política educativa es todavía una nueva y aun en gran parte inexplorada área de investigación. En esta línea, conviene significar, siquiera de forma sucinta, algunas contribuciones de los procesos etnográficos a los principales enfoques de investigación de la ciencia política: formalismo, estudios de poder, utilidad y de la decisión y enfoque de grupos ${ }^{18}$.

A veces, se ha querido identificar la historia de la política educativa con el formalismo, que se presenta como el enfoque más antiguo en ciencia

16 Agustín Escolano y Jose María Hernández (coords.), La memoria y el deseo. Cultura de la escuela y educación deseada (Valencia: Tirant lo Blanch, 2002).

17 Umberto Eco, "Prólogo", en El discurso histórico, ed. Jorge Lozano (Madrid: Alianza Editorial, 1994).

18 Jay D. Scribner y Donald H. Layton (Eds.), The study of educational politics (Washington-London: The Falmer Press, 1995). 
política empírica. Identifica, a efectos prácticos, la política con las normas e instituciones vigentes en una comunidad, lo que explica en parte su dependencia jurídica. El objeto de estudio se circunscribe a las estructuras legales, que incluyen tanto las organizaciones gubernamentales formales y el derecho que las rige, como las leyes constitucionales, orgánicas o equiparables y sus interpretaciones en la práctica política. La metodología etnográfica -aunque lógicamente ajustada y limitada al objeto de esta visión del trabajo, consistente básicamente en localizar, compilar y clasificar el material objeto de estudio- evidencia cómo la historia política no se agota en la esfera oficial, sino que tiene mayor alcance, toda vez que permite analizar el impacto de estas pautas en el comportamiento de los actores, intentando establecer también las condiciones en que opera la estructura social dentro de la política de un Estado en un tiempo determinado.

Especial interés puede representar el impacto en el enfoque centrado en los estudios de poder que, como el anterior, arranca desde los primeros momentos de institucionalización de la ciencia política empírica moderna, y donde la oralidad y las entrevistas en profundidad a testigos directos pueden contribuir a fortalecer los estudios que a lo largo de los últimos años se han ido produciendo en busca no solo de encontrar las élites, sino también medirlas y ver cómo evolucionan e interactúan.

El diseño etnográfico ha contribuido también al fortalecimiento de la corriente de investigación denominada utilidad de la decisión política (rational choice). La teoría de la elección racional, producto surgido fuera del campo de la ciencia política, fundamentalmente en los círculos matemáticos y económicos, lleva camino de convertirse en una de las más fructíferas. Su objetivo es la construcción de un modelo lógico que, proyectado sobre los hechos sociales, nos ayude a explicar su génesis y desarrollos. Y en esta tarea cobra sentido la consideración de las percepciones, los discursos y sobre todo las diferentes estimativas de los actores políticos.

228 Por último, nos referimos al enfoque de grupos como línea de investigación de la política, que fuera expuesto de forma articulada y explícita por primera vez en 1908 por Arthur Fisher Bentley en su libro The Process of 
Government. A Study of Social Pressures ${ }^{19}$. El punto de atención básico se sitúa en el grupo y no en el individuo, ya que se parte del supuesto de que el primero tiene mayor influencia que el segundo en el diseño de los procesos políticos. En su conjunto, los estudiosos de esta corriente contemplan el sistema político como una malla gigante de grupos en constante interacción mediante presiones y contrapresiones cuya resultante final define los objetivos y situación del sistema político. Se trata de una línea de investigación de gran interés, donde la incorporación de la etnografía, repensando el sujeto, ha contribuido a resolver importantes problemas asociados a la lógica de la acción colectiva, a la participación en la política educativa, a las explicaciones de equilibrio y funcionalidad de los sistemas y organizaciones educativas y a los procesos de modernización escolar ${ }^{20}$.

En nuestro recorrido por las principales tendencias de investigación empírica en política, hemos ido advirtiendo la frescura y sintonía que puede proporcionar el recurso a la oralidad y al testimonio del sujeto de la política educativa. No se trata de una simple moda, ni comporta una desviación metodológica. El recurso a estas nuevas fuentes y su contraste y triangulación con los documentos de archivo y la literatura científica contribuye a fundamentar la explicación de la historia de la política educativa, interdisciplinaria y metodológicamente plural, en el contexto más realista posible, reinterpretando el orden del discurso del $\operatorname{poder}^{21}$ y la lógica de sus prácticas con un sentido de totalidad ${ }^{22}$.

\section{ETNOGRAFÍA Y REFORMA EDUCATIVA REPUbLICANA EN ESPAÑa}

Las consideraciones hasta ahora expuestas nos conducen a éxplicar de

19 Arthur Fisher Bentley, The Process of Government,.A Study of Social Pressures (Chicago: University of Chicago Press, 1908).

20 Véanse, entre otros: Carmen García Colmenares y Luz Martínez Ten, La escuela de la República. Memoria de una ilusión (Madrid: FETE-UGT, La Catarata, 2014); Angel Serafín Porto y Raquel Vázquez, La escuela activa y el entorno. Una aproximación a través de los paseos, visitas y excursiones durante la Segunda República (Santiago de Compostela: Andavira, 2017).

21 Michel Foucault, L'Ordre du discours. Leçon inaugurale au Collège de France prononcée le 2 décembre (París: Gallimard, 1970) (Traducción: El orden del discurso, Barcelona: Tusquets, 1987).

22 Véanse, entre otros: Julio Ruiz Berrio (ed.), La cultura escolar de Europa. Tendencias históricas emergentes (Madrid: Biblioteca Nueva, 2000); Pedro Luis Moreno y Antonio Viñao, Imagen y educación: marketing, comercialización y didáctica. España, siglo XX (Madrid: Morata, 2017). 
manera concreta e inmediata qué es y en qué consiste repensar el sujeto en la historia de la política educativa, tratando de mostrar su fecundidad heurística y concretar las ventajas asociadas a esta actitud metodológica de dar voz a los protagonistas, focalizando nuestra atención en el estudio de la política educativa republicana en España (1931-1936), un ciclo bien significativo y documentado de la historia de la administración general y educativa, que exhibe profundas transformaciones operadas bajo la influencia, entre otros factores, de los complejos mapas de situación, disputadas demarcaciones y equilibrios de poder que genera la vida pública española en esta época ${ }^{23}$.

El corpus de trabajos sobre la obra educativa llevada a cabo en este corto, pero decisivo, período de nuestra historia contemporánea enfatiza, con ligeras variantes, el influjo de un importante cambio de mentalidad y tendencia social, manifestado de forma particular en la institucionalización de un ciclo cultural de especial significación pedagógica ${ }^{24}$. Además, balances historiográficos, como la exhaustiva revisión de la investigación histórico-educativa producida en España, cuya edición fue cuidadosamente preparada por los profesores Jean Louis Guereña, Julio Ruiz Berrio y Alejandro Tiana ${ }^{25}$, nos reafirman en el interés de esta importante coyuntura histórica por sus repercusiones en los procesos de escolarización en nuestro país y que, por lo demás, han motivado algunas de nuestras publicaciones $^{26}$.

23 Fernando Cos Gayón, Historia de la Administración Pública en España (Madrid: Escuela Nacional de Administración Pública, 1976).

24 Véanse, entre otros: Antonio Molero Pintado, La reforma educativa de la Segunda República Española (Madrid: Edicusa, 1975); Historia de la Educación en España, Vol IV, La educación durante la Segunda República y la Guerra Civil (1931-1939) (Madrid: MEC, 1991); Mariano Pérez Galán, La enseñanza en la Segunda República Española (Madrid: Edicusa, 1975); Mercedes Samaniego Boneu, La política educativa de la Segunda República durante el bienio azañista (Madrid: CSIC, 1977).

25 Jean Louis Guereña, Julio Ruiz Berrio y Alejandro Tiana Ferrer (eds.), Historia de la educación en la España contemporánea. Diez años de investigación (Madrid: CIDE, 1994).

26 Véanse: Alfredo Jiménez Eguizábal, La inspección de Primera Enseñanza en la Segunda República Española (Salamanca: Universidad de Salamanca, 1984); Carmen Palmero Cámara, Educación y Sociedad en La Rioja Republicana (1931-1936), (Salamanca-Logroño: Universidad Pontificia de Salamanca-Gobierno de La Rioja, IER, 1990); “La Escuela Republicana en Burgos”, en La Escuela Primaria en Castilla y León, ed. José María Hernández Díaz (Salamanca: Amarú Ediciones, 1993), 139-158. 
La llegada de la Segunda República, en la primavera de 1931, supuso un camino hacia la modernidad ${ }^{27}$ y un hito fundacional: "-un tiempo por escribir desde las auras de libertad y los renovados ideales de regeneración de la patria que el cambio de régimen político traía- ${ }^{28}$.

La sociedad española -cambiante y en crisis fundamentalmente a partir de 1917, con antecedentes en $1898^{29}$ - inicia en treinta y seis horas decisivas del 13 y 14 de abril de $1931^{30}$ una experiencia político-social esperanzadora $^{31}$, cuyo punto de partida se halla en el legado histórico que asume y que la Revista de Escuelas Normales -órgano de la asociación nacional de su profesorado numerario- resume en tres categorías muy expresivas: "inmoralidad, despilfarro e incultura" 32 . La República "como forma de ser nacional"33 dispondrá de 1920 días para modificar su problemática coyuntural y estructural.

Las principales notas que se presentan en la evolución de España durante el primer tercio del siglo XX -y que convergen en 1931 con diferente formulación del problema nacional- exigen la adaptación de un nuevo modelo educativo, originando un verdadero problema pedagógico. En una referencia sintética y generalizadora, afrontamos una coyuntura histórica con una problemática específica, en general adversa y restrictiva, de la que destacamos algunos aspectos con notables implicaciones educativas.

El primer tercio del siglo XX, especialmente el decenio 1921-1930, significa para España un importante crecimiento demográfico que determina

27 Agustín Escolano y Rogério Fernandez (eds.), Los caminos hacia la modernidad educativa en España y Portugal (1800-1975), (Zamora: SEDHE, Fundación Rei Afonso Henriques, 1997).

28 Agustín Escolano, “Introducción”, en El niño republicano, ed. Joaquín Seró Sabaté (Madrid: Edaf, 2000), I.

29 Jaime Vicens Vives, Historia social y económica de España y de América (Barcelona: Vicens Vives, 1977), 350-383.

30 Horas decisivas que son relatadas con detalle en Joaquín Arrarás, Historia de la Segunda República española I (Madrid: Editora Nacional, 1956), 7-41; Manuel Tuñón de Lara, La España del siglo XX, II (Barcelona: Laia, 1974), 383 y ss.

31 «emánticamente, la palabra República era compendio de esperanzas políticas». Claudio Lozano Seijas, La educación republicana (Barcelona: Universidad de Barcelona, 1980), 35

32 Revista de Escuelas Normales 89 (1932): 137.

33 Declaración de D. Manuel Azaña en su discurso en la sesión de clausura de la Asamblea Nacional de Acción Republicana. El Sol 29 de marzo de 1932. 
el alza de la población escolar de 1931 provocando un agudo problema de escolarización, debido a que en general, y sobre todo en los niveles básicos, la demanda de educación no puede ser satisfecha, entre otras razones, por el escaso número de maestros y escuelas, además de cierta desidia política, mal estado de las escuelas e insuficiente formación de los maestros, como habían puesto de manifiesto los distintos viajes por las escuelas de España de Luis Bello ${ }^{34}$. Los dirigentes republicanos deberán profundizar en el análisis de este fenómeno e implantar, prioritariamente, adecuados mecanismos -más escuelas y mejores maestros, junto a una mayor intensidad y énfasis en su función social- que contribuyan decisivamente a alcanzar el objetivo de democratizar la educación.

Sin embargo, este objetivo, con todos sus adjetivos de universalidad, obligatoriedad y gratuidad, difícilmente va a poder ser abordado sin una continuidad en las directrices de la política encargada de racionalizar el proyecto de España contenido en la Constitución de 9 de diciembre de 1931. Las oscilaciones de un débil sistema de partidos y la inestabilidad del consenso republicano van a ser claros obstáculos en los proyectos de resolución de las contradicciones sociales, religiosas, económicas y culturales que deberá afrontar la República ${ }^{35}$.

Otros aspectos que resultan significativos constatar están relacionados con un marco internacional en estado crítico $^{36}$ y con las reformas -militar, eclesiástica y agraria, entre otras ${ }^{37}$ - que la Segunda República se ve obligada a emprender, originando una dispersión de fuerzas que explica la

34 Luis Bello, I. El cerco de Madrid; viaje a la sierra; por Castilla y León; Asturias; el prejuicio contra el maestro; la Sociedad de Amigos de la Escuela- II. Por Andalucía: Cádiz, Málaga, Granada; Las dos Castillas: Toledo, Soria - III. Extremadura: suma de varios viajes, Cáceres y Badajoz, cien kilómetros en Portugal- IV. Más Andalucía: las siete Huelvas, Sevilla: viaje preliminar; viaje de instrucción a Tánger; Jaén: viaje a Santiago de la Espada (Madrid: Magisterio Español, 1926-1929)

35 Véanse: Niceto Alcalá-Zamora, Los defectos de la Constitución de 1931 (Madrid: Espinosa, 1936); Arturo Mori, Crónica de las Cortes Constituyentes de la II República Española (Madrid: M. Aguilar, 1932).

36 Juan José Carreras, "El marco internacional de la II República”, Arbor 426-427 (1981): 37-50.

37 Véanse: Eduardo Espín Templado, "El panorama militar", Revista de Occidente 7-8 (1981): 39-57; Arxiu Vidal i Barraquer, Esglesia i Estat durant la Segona República Espanyola (1931-1936). Edición presentada y comentada por Miquel Batllori y Victor Manuel Arbeloa (Barcelona: Abadía de Montserrat, 1971-1977); Francisco Díaz de Arcaya, La reforma agraria de 15 de septiembre de 1932. Comentada con su doctrina parlamentaria y disposiciones complementarias (Madrid: Reus, 1935). 
limitada respuesta a las constantes demandas de mejoras económicas para la educación que se producen durante la coyuntura republicana, lo que va a condicionar decisivamente el objetivo de generalizar la escolarización.

Toda esta fenomenología política, económica y social resulta pertinente para comprender que desde el principio la Segunda República pretendiera significarse por su condición de período de reforma de la educación, sustentándose para ello en una extraordinaria acumulación ideológico-cultural con base en las generaciones de 1898, 1914 y 1927, la denominada metafóricamente como España excesiva. Unos objetivos reformadores, con notables efectos en el pensamiento pedagógico y en las prácticas educativas, en los que van a confluir fundamentalmente los principios del liberalismo, la moderna pedagogía de los institucionistas, así como el peso específico del proyecto educativo socialista ${ }^{38}$.

La cuestión obviamente no podía reducirse a sustituir el retrato del rey D. Alfonso XIII de las escuelas, la Segunda República, para significarse por su condición de período de reforma de la educación, tenía que delimitar objetivos en el campo del pensamiento, de las instituciones y del proceso de escolarización. Bajo la tutela estatal, se impulsarán decididamente desde las primeras medidas legislativas los principales ejes reformistas: establecimiento del laicismo, escuela unificada y profunda renovación metodológica $^{39}$. Objetivos reformistas de la política educativa republicana, que mostrarán una especial sensibilidad hacia la escuela primaria-base del sistema educativo y en general del progreso social- que se percibe como el problema prioritario. La República tenía el deber imperativo de resolver una cuestión resuelta en toda Europa: el problema de la escuela prima-

38 Resulta relevante subrayar el importante papel de impulso y difusión de la política educativa republicana que es preciso atribuir al Boletín de la Institución Libre de Enseñanza y de la Revista de Pedagogía, así como el papel de comunicación de noticias y experiencias entre profesionales de la educación que tienen la Revista de Escuelas Normales y El Magisterio Español. Véanse, entre otros: Revista de Escuelas Normales 89 (1932): 136; 106 (1935): 1; Revista de Pedagogía 136 (1933): 186; El Magisterio Español, 26 de enero de 1932; 10 de enero de 1933.

39 El reflejo en la prensa de estas medidas fue lógicamente dispar. Posición de equilibrio, el diario El Sol. Paladín de la crítica, El Debate. En apoyo al contenido de las principales disposiciones legislativas del gobierno republicano, El Socialista. 
ria $^{40}$. Y en esta línea se acometió una reforma del aparato administrativo poniendo en marcha los Consejos de protección escolar y reformando la inspección educativa, un ambicioso plan de creación de escuelas a través de un plan quinquenal, una radical transformación de la formación profesional de maestros, el decidido impulso de las instituciones relacionadas con la primera enseñanza y el cuidado de la escuela por dentro. Marcelino Domingo, maestro de primera enseñanza y Ministro de Instrucción Pública en 1931 y 1936, dirigiéndose a los inspectores y maestros afirma: "No basta convertir la enseñanza primaria en un problema de cantidad de escuelas suficientes. La calidad es un imperativo de gobierno paralelo a la cantidad. La Escuela ha de ser taller y jardín"41.

El examen de la cuestión planteada nos ha conducido a exponer las principales tesis que forman parte del registro objetivo de la cultura político-pedagógica de la coyuntura republicana, significada, sin duda, por su condición de período de reforma de la educación -aparato administrativo, escuelas y maestros, renovación metodológica-, orientada hacia un objetivo primordial que al final de la experiencia republicana quedaría incumplido: la promulgación de una Ley de Instrucción Pública.

Un balance equilibrado de la coyuntura republicana denota la existencia de un contraste entre las aspiraciones de 1931 y los resultados de 1936 en algunos aspectos cruciales como la creación de escuelas, reducidas a la mitad de las planificadas, la formación profesional de los maestros excesivamente contestada, la revitalización, solo cumplida parcialmente, de la escuela por dentro, entre otras realidades. En cierto sentido fue la coyuntura de las buenas intenciones, que se vieron truncadas de forma abrupta por la Guerra Civil el 18 de julio de 1936. Pero estas limitaciones, no invalidan, más bien, por el contrario, refuerzan y ponen en valor el leit motiv de la política educativa republicana de convertir la escolarización, tanto en su dimensión cuantitativa, como cualitativa, en una cuestión fundamental de Estado.

40 Marcelino Domingo, Le escuela en la República (La obra de ocho meses) (Madrid: M. Aguilar, 1932). Véase también: Rodolfo LLopis, La revolución en la escuela. Dos años en la Dirección general de Primera enseñanza (Madrid: M. Aguilar, 1933).

41 Revista de Escuelas Normales 119 (1936): 123. 
Pero si nos preguntamos ahora en torno a cómo esas medidas reformistas quedaron plasmadas en la cultura y en las prácticas empíricas de las escuelas, sobre el efecto real e interpretado de las disposiciones y cambios legislativos, las significaciones culturales y el sentido acordado que en la colectividad de maestros generó la escuela unificada, los códigos y los cambios efectivos en la escuela por dentro, las percepciones y los sentimientos de la comunidad educativa, sobre cómo se aplicó la reforma y cómo se practicaron las nuevas metodologías y las relaciones didácticas nos encontramos con un repertorio de interrogantes de interés general que solo podremos afrontar con cierta solvencia y garantías de éxito a través de las líneas etnográficas y microhistóricas de la nueva historia cultural en la que se abren paso el sujeto y la oralidad.

Consecuentemente, la construcción del trabajo nos remite, más allá de los fondos archivísticos y la literatura científica, a una historia con palabras, al contraste con la voz y los testimonios directos de quienes participaron en la gestión de la experiencia republicana, y que, por lo demás, han ido desapareciendo -fugit irreparabile tempus ${ }^{42}$-. Para producir conocimiento histórico, no simplemente un relato ordenado de vida y experiencia, y también para avanzar conceptualmente, vertebrar las experiencias y lograr una visión de conjunto, planificamos los componentes esenciales de las entrevistas a maestros e inspectores -las preguntas o problemas que se pretenden investigar, proposiciones acerca de cómo se puede responder a esos interrogantes, la unidad de análisis y la lógica que conecta los datos con las proposiciones- y nos adentramos en el muestreo por referencia en cadena $^{43}$. Contactamos con unos pocos maestros e inspectores que presentaban el perfil deseado. Esas personas identificaron a otras que fueron incluidas en la muestra y así sucesivamente hasta lograr medio centenar de participantes.

Ahora bien, para comprender correctamente la identidad y dimensiones

42 "Sed fugit interea, fugit irreparabile tempus / singula dum capti circumvectamur amore" (Pero entre tanto huye, huye irreparable el tiempo, mientras nos demoramos atrapados por el amor hacia los detalles). Virgilio, Geórgicas, libro III (vv. 284-285).

43 Patrick Biernacki y Dan Waldorf, "Snowball sampling: Problemas and techniques of cain referral sampling", Sociological Methods and Research 10 (1981): 141-163. 
de la educación en torno a la coyuntura republicana, incluso para valorarla -rastreando el poder y con el afán de demostrar la importancia de la educación para un estado soberano ${ }^{44}-$, consideramos oportuno - siguiendo en este sentido uno de los dictámenes más consensuados de la ciencia política contemporánea ${ }^{45}$ - que nuestro discurso, desde sus primeros análisis, se interese por generar, además del registro del impacto y efectividad de las estructuras legales y normas institucionales, argumentos y respuestas a los problemas más significativos de la función social de la educación y de la escuela, elevando también a objeto fundamental de investigación la explicación de los procesos y mecanismos de la acción educadora, mostrando cómo emergen distintas formas de regulación social del poder. Lógicamente, intentamos seleccionar temas de estudio que no solo sean teóricamente apasionantes, sino también de primera importancia práctica.

En lo que afecta a la cuestión metodológica, desde el mismo inicio de nuestro planteamiento investigador ya éramos plenamente conscientes de que asumíamos riesgos al emprender una tarea de observación, registro y descripción sometida a numerosas limitaciones y condicionantes fisiológicos, psicológicos, sociales y culturales. Por ello, especial interés metodológico representó para nosotros, introducirnos en la medida de lo posible en su entorno natural, aprendiendo y compartiendo su mundo de significados, sin establecer límites temporales, lo que nos facilitó la realización de entrevistas, el acceso directo a temas, documentos y aspectos de la vida cotidiana, contrastar la información y observar las reacciones al problema. $\mathrm{Y}$ de esta manera, fuimos a lo largo de las últimas décadas del siglo XX realizando entrevistas, obteniendo apuntes, notas de campo, agenda, diario personal, grabaciones en audio e informes manuscritos y mecanografiados $^{46}$, tal y como aparecen ejemplificados en la Figura 1:

44 Manuel de Puelles Benítez, "Política de la educación. Viejos y nuevos campos de conocimientos", Revista de Ciencias de la Educación 178-179 (1999): 187-206.

45 David Easton, A framework for political analysis (New Jersey: Prentice-Hall, 1965).

46 Indicamos los Informes de los maestros e inspectores seleccionados para este trabajo con un breve apunte biográfico: Salvadora Devesa Cano, nacida en Alicante el 3 de abril de 1908, maestra normal, número 226 del Escalafón, con destino en Cádiz, número 2 de las oposiciones de 1932 e ingreso en el cuerpo el 19 de noviembre de 1932. Francisca González Rivero, nacida en Santander el 17 de enero de 1900, maestra normal, número 215 del Escalafón de 1935, con destino en Navarra, número 17 de la promoción de 1925 de la Escuela de Estudios Superiores del Magisterio, con ingreso en el Cuerpo 


\section{$-2-$}

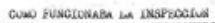

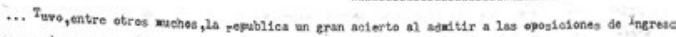

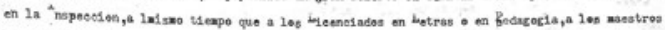
en netivo, que llevagen deterninades anos de serwieles ... So entendile,y no sin fundamento, que no se puede orlentas ni dirigir en las labore, docentes priserias sin haber oido antes - sestro,

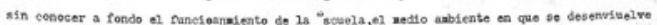

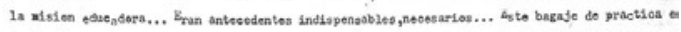

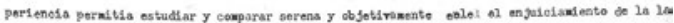

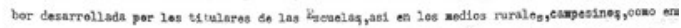

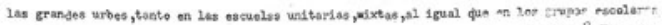

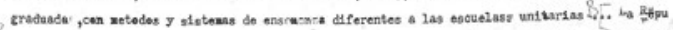

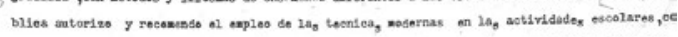

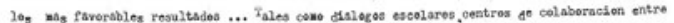

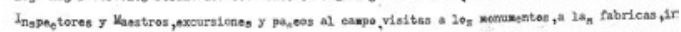

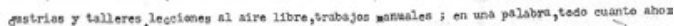
constituye 2a actualsdad oduoativa o instruetsva ... Pue una etpecie de "renacialento" ...

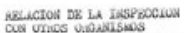

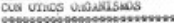

-... Para su major perfoceleosudento y egtar al dia, in Inspeocion mantenta constantes rolaciones

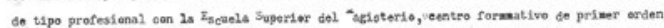

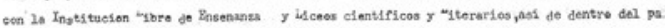

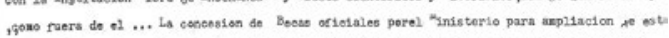

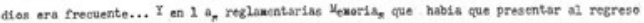

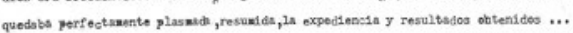

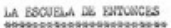

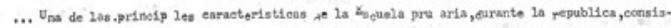

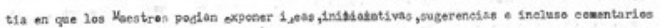

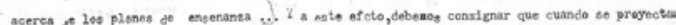
ba alguna reform, niempre se coneultabn el poreoer de 105 estamentos afoctados, en un gesto ef1

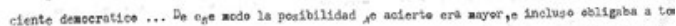

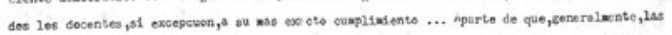

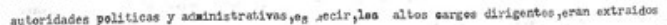

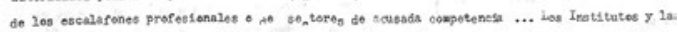

\author{
Addolfo Maillo Sarcia \\ Madrid-3 21 - febrero - 1980

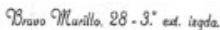 \\ Telefano 4467394
}

Sr.D. Juna Alfredo Jiménez

Salamanaa

\begin{abstract}
Querido anigo:Le remito adjuntos los dotos que se solie t6 con fecha $1^{4}$ do enero $y$ que has ta ahora no he podido curplise? tar por otras ocupaciones urgentes, por 10 que le pido disculpas. Supongo que con ellos contesto al Cuestionario quo mo on. vib.no obstante, si hay algún aspecto sobre cl que desee thas tocamentación viva,estoy a su disposición. Con este motivo, queda suyo affmo,amico,
\end{abstract}

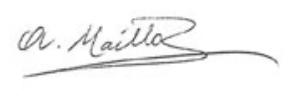

Figura 1. Informes de maestros e inspectores:

D. Alejandro Manzanares Beriaín y D. Adolfo Maillo García

Fuente: Archivo personal

el 6 de junio de 1932. Antolín Herrero Porras, nacido en Palencia el 1 de septiembre de 1901, maestro normal, número 263 del Escalafón con destino en Palencia, número 39 de la oposición de 1932 e ingreso en el cuerpo el 19 de noviembre de 1932. Alfonso Iniesta Corredor, nacido en Albacete el 7 de febrero de 1901, maestro, número 345 del Escalafón, con destino en Orense y número 42 de las oposiciones de 1934 e ingreso el 21 de diciembre de 1934. Adolfo Maíllo García, nacido en Cáceres el 25 de mayo de 1901, maestro, número 240 del Escalafón, con destino en Salamanca, número 16 de las Oposiciones de 1932 e ingreso en el cuerpo el 19 de noviembre de 1932. Alejandro Manzanares Beriaín, nacido enVizcaya el 10 de marzo de 1894, maestro, número 327 del Escalafón, con destino en Vizcaya y número 24 de las oposiciones de 1934 e ingreso el 21 de diciembre de 1934. Luis María Mestras Martí, nacido en Gerona el 23 de mayo de 1902, maestro normal, número 300 del Escalafón, con destino en Baleares y número 1 de las oposiciones de 1931 e ingreso el 11 de enero de 1934. José Muntada Bach, nacido en Barcelona el 24 de septiembre de 1900, maestro normal, número 301 del Escalafón, con destino en Pontevedra y número 12 de las oposiciones de 1931 e ingreso el 11 de enero de 1934. Cipriano Pinés Espadas, nacido en Ciudad Real el 23 de septiembre de 1902, maestro normal y licenciado, número 272 del Escalafón, con destino en Valencia y número 48 de la oposición de 1932 e ingreso el 19 de noviembre de 1932. Ubaldo Ruiz Tablado, nacido en Burgos el 16 de mayo de 1905, maestro normal, número 225 del Escalafón, con destino en Ávila, número 1 de las oposiciones de 1932 e ingreso en el cuerpo el 19 de noviembre de 1932. 
Coherentes con el carácter limitado y comprensivo de este trabajo, aludiremos de forma sintética a los principales ámbitos y sistemas de mediación sobre los que los testimonios recogidos aportaron y siguen aportando hoy argumentos decisivos y elementos de contraste para el conocimiento en profundidad de la reforma educativa republicana.

Desde la perspectiva del análisis histórico-pedagógico general, debemos subrayar los amplios conocimientos científicos y técnicos, así como el equilibrio y la madurez intelectual y humana de los inspectores y maestros entrevistados. Estamos convencidos de que estas cualidades personales deben atribuirse en gran parte al impacto formativo de la Escuela Superior del Magisterio, creada por Real Decreto de 3 de junio de 1909 para mejorar la formación profesional de los futuros inspectores y profesores de escuelas normales ${ }^{47}$. Una institución pionera en la formación superior de los docentes e inspectores con 23 años de historia y más de setecientos alumnos formados a lo largo de sus veintidós promociones: "La supresión de la Escuela de Estudios Superiores del Magisterio en 1932 fue un duro golpe para la Inspección y las Escuelas Normales. De ella había salido un gran contingente de inspectores jóvenes que llevaron a las provincias los aires renovadores de las modernas teorías pedagógicas"48.

Las entrevistas con maestros e inspectores, aunque en los primeros contactos aparecían como pinceladas y reflexiones complementarias, permitieron introducir paulatinamente nuevos elementos y variables - unas veces de carácter compilador, otras con carácter más específico- en el conocimiento sobre la educación republicana, además de facilitarnos numerosas publicaciones impresas de la época y utillaje material. Buena parte de las señas de identidad más específicas de la reforma educativa han podido definirse y matizarse suficientemente por los testimonios aportados sobre la organización pedagógica de la escuela, el trabajo escolar, los sistemas de

47 Alfredo Jiménez Eguizábal, "Evolución institucional de la Escuela de Estudios Superiores del Magisterio. Objetivos y contenidos a través de los planes de estudio", en Escuela de Estudios Superiores del Magisterio (1909-1932). Un precedente histórico en la Formación Universitaria del Profesorado Español, eds Antonio Molero Pintado y María del Mar del Pozo Andrés (Madrid: Universidad de Alcalá, 1989).

48 Cita textual extraída del Informe personal correspondiente a D. Luis María Mestras. Audio y 6 folios mecanografiados. 
aprendizaje, los componentes curriculares y por la forma de resolver los problemas cotidianos. Atendiendo a los datos y argumentos contenidos en los testimonios, que todavía hoy siguen emitiendo señales que suscitan nuevos estudios, hemos podido enfocar la verdadera fisonomía de la escuela republicana, necesariamente sometida a contraste con la archivística disponible, tales como expedientes, libros de correspondencia escolar, libros de visita de inspección y boletines de educación.

A nuestro modo de ver, tres importantes y nucleares aspectos de la reforma educativa republicana van a quedar nítidamente reflejados y proyectados a través de la historia oral, cuyos apuntes nos proporcionan informaciones precisas y los contrastes necesarios para valorar correctamente los nexos y disfunciones entre las pretensiones legislativas, los discursos teóricos de las reformas pedagógicas y la praxis escolar:

a) El amplio debate pedagógico que se genera en torno al ideario educativo republicano y que abre ciertamente nuevas perspectivas para la escuela.

b) La modificación de la administración educativa a través de la creación de los Consejos de protección escolar de primera enseñanza y la reforma de la Inspección educativa, con importantes efectos y repercusiones en los ámbitos provinciales.

c) El alcance del movimiento reformista en la creación de escuelas, la formación de los maestros, cambios organizativos, curriculares y materiales en la escuela y pujanza de la extensión educativa y la cultura popular.

Un primer conjunto de datos e informaciones contenidas en la oralidad de maestros e inspectores alude al debate ideológico y a las implicaciones de una política escolar concebida como arma ideológica de la revolución española, que va a desencadenar un cambio de mentalidad colectiva en relación con la imagen social de la educación: "Escuela nueva con espíritu nuevo. ... de la tolerancia, de la solidaridad, escuela sin barreras lingüísticas, ni raciales, ni religiosas, ni de costumbres: escuela de la más profunda humanidad". ${ }^{49}$

En esta línea, los testimonios reflejan puntualmente el nivel de expecta-

49 Boletín de Educación de Palencia 1 (1933):1. 
ción y las actitudes y comportamientos de las asociaciones del magisterio con implantación en las diferentes provincias: "Cabe señalar, la intensa movilización y dinámica asociativa del magisterio en busca de una escuela primaria obligatoria y gratuita en todos los grados" ${ }^{\circ 0}$. De forma convergente con esta afirmación, encontramos significativas valoraciones en torno a iniciativas de gestación territorial del Frente Único del Magisterio con la novedosa propuesta de acción conjunta por regiones ${ }^{51}$, así como las acciones emprendidas por las secciones provinciales de la Federación de Trabajadores de la Enseñanza ${ }^{52}$. Recuerdos de maestros e inspectores que ponen de manifiesto las movilizaciones que llevaron a cabo las distintas asociaciones de estudiantes del magisterio a favor de una escuela unificada: "Los maestros eran proclives a la renovación metodológica, conocían las innovaciones pedagógicas europeas a través de la prensa profesional, y en su mayoría participaban en movimientos asociativos" ${ }^{53}$.

Actitudes y comportamientos que ponen de relieve la actitud generalizada de apoyo con que contó buena parte de la normativa educativa emanada del Ministerio. En la implantación del nuevo ideario educativo republicano, a pesar de las controversias sociales suscitadas por alguno de sus puntos básicos como el laicismo escolar y los consecuentes intentos de sustitución de la enseñanza impartida por las Órdenes Religiosas, se advierte una gran confianza en la escuela como vehículo de renovación de la sociedad a través de la transformación individualizada de los ciudadanos, suscitándose inevitablemente la necesidad de modernizar el sistema educativo con especial énfasis en la primera enseñanza y en la educación popular: "Es innegable que la República significó desde sus inicios una

50 Cita textual extraída del Informe personal correspondiente de D. Cipriano Pinés Espadas. Audio y 2 folios mecanografiados.

51 "Ha quedado constituido en esta provincia el Frente Único del Magisterio primario, integrado por representantes de las tres Asociaciones: Nacional, Trabajadores y Confederación. Ha tomado los siguientes acuerdos: Dirigirse a la Comisión del Frente Único del Magisterio de Valladolid interesando se estudie la posibilidad de actuar conjuntamente las Asociaciones profesionales de la región castellano-leonesa”. Boletín de Educación de Palencia 6 (1934): 12

52 Véase: Libro de Actas de Sesiones del Ayuntamiento de Burgos. 12 de julio de 1933. Folio 101.

53 Cita textual extraída del Informe personal correspondiente a Doña Francisca González Rivero. Audio y 9 cuartillas manuscritas. 
renovada confianza en la educación, un estímulo para los maestros y un claro avance en la escolarización" ${ }^{54}$.

En segundo lugar, hay que aludir al impacto de la reforma de la administración educativa. Desde la Gaceta de Madrid podía impulsarse un determinado modelo educativo, pero su eficacia pasaba necesariamente por la reforma del aparato administrativo que, además de la reorganización del Consejo de Instrucción Pública, en los niveles municipales y provinciales va a tener una marcada incidencia a través de los Consejos de protección escolar y de la Inspección educativa.

$\mathrm{Y}$ es que, en efecto, aunque diversas instituciones de representación política -gobierno civil, diputación- estuvieron implicadas, con diferentes niveles de responsabilidad, en la construcción de la escuela pública, son los ayuntamientos los principales gestores de las medidas reformistas. La documentación producida por los Consejos de protección escolar ponen bien de manifiesto el compromiso de la mayor parte de las corporaciones municipales que se manifiesta en el esfuerzo presupuestario por destinar a instrucción pública cantidades significativas, además de las obligaciones contraídas en el proceso generalizado de petición de construcción de escuelas, así como por su papel activo en los Consejos locales de protección escolar, reflejando una profunda preocupación por el funcionamiento de la escuela y por superar su tradicional aislamiento. Iniciativas que se ven corroboradas, aunque rebajadas en su nivel de éxito, por los testimonios de los propios inspectores: "Dejábamos constancia en nuestras visitas de las dificultades y aislamiento de los maestros, visitando al alcalde siempre dispuesto a escuchar, si bien en ocasiones se tornaba difícil encontrar la solución del problema" 55 .

El cotejo de la oralidad y testimonios de maestros e inspectores con el contenido de los Libros de Actas de los Consejos de protección escolar ${ }^{56}$ y de los Libros de visitas de inspección, al tiempo que dan cuenta de la

54 Cita textual extraídas del Informe personal correspondiente a D. Alejandro Manzanares Beriaín. Audio y 7 folios mecanografiados.

55 Cita textual extraída del Informe personal correspondiente a Doña Salvadora Devesa Cano.

56 Archivo Histórico Provincial de Logroño. Libro de Actas de Sesiones del Consejo Local de Primera 
nueva orientación pedagógica de la inspección educativa, nos proporciona datos de innegable valor en torno a la descripción de la escuela en sus aspectos materiales, tales como dotación, ubicación y tipo, calidad de local y cantidad del material, información sobre la matrícula y asistencia media de los alumnos, aspectos de la organización y enseñanza, proporcionando datos y evidencias sobre las relaciones escuela-sociedad, que expresan la presencia o ausencia de colaboración entre ambas ${ }^{57}$. Por los textos vivos hemos conocido deficiencias generalizadas en la iluminación y ventilación de las escuelas, así como la escasa dotación de material fijo y móvil. Los informes recogidos también nos han permitido aquilatar el sentido y alcance de las funciones administrativas: expedientes de construcción de edificios escolares, aprobación de presupuestos de material escolar, nombramientos de maestros interinos y concesión de licencias, entre otras.

Los testimonios aluden, de forma paralela a los libros de actas y de visitas, a la preocupación por los aspectos materiales de la educación, pero inciden también en sugerentes aspectos higiénicos y estéticos, que reflejan la penetración en el pensamiento pedagógico de las ideas paidológicas: "El higienismo y el respeto al niño formaba parte del día a día en las escuelas, los maestros" 58 . Así, podemos comprobar cómo las iniciales preocupaciones por el cumplimiento de las ordenanzas y la fiscalización de actividades se habían ido transformando en certeras orientaciones didácticas y organizativas, vehiculadas sobre todo a través de los informes de las visitas de inspección, cuyo conjunto perseguía el propósito explícito de transformar la escuela por dentro, si bien integrado en su constitución por elementos ideológicos muy diversos ${ }^{59}$.

En tercer lugar, focalizamos nuestra atención investigadora en el alcance

24258 Cita textual extraída del Informe personal correspondiente a D. Ubaldo Ruiz Tablado. Audio y 2 cuartillas manuscritas.

59 Rafael Álvarez, Juan Comas y Juvenal de Vega, Manual del inspector de Primera Enseñanza (Madrid: Publicaciones de la Revista de Pedagogía, 1934) 
del denso movimiento de reforma pedagógica emprendida con importantes efectos organizativos y curriculares.

Los testimonios dan cumplida cuenta de la importancia concedida por el movimiento reformista a los aspectos pedagógicos, desde la fijación del almanaque escolar, hasta el ensayo de nuevos métodos docentes: "en las visitas de inspección no solo comprobábamos aspectos concretos de la vida escolar, sino que hacíamos lecciones modelo seguidas de crítica y proponíamos la adquisición y renovación del material" 60 . Acertada orientación pedagógica que resulta coincidente y se refuerza a través del análisis del contenido del Boletín de Educación ${ }^{61}$, puesto en marcha por la política educativa republicana como mecanismo formativo del magisterio y como instrumento de colaboración de maestros e inspectores: "En los Boletines se informaba de las últimas disposiciones del Ministerio, con las normas para su aplicación. Insertaba el Boletín provincial trabajos útiles. Hasta los niños podían intervenir con sus trabajos en equipo ${ }^{\prime 2}$.

El contraste del estudio material del Boletín de Educación con las informaciones proporcionadas a través de los propios inspectores y maestros nos permite afirmar la tesis sobre la difusión y efectividad del Boletín, que se articula como una vía de coordinación y difusión pedagógica, necesaria desde el punto de vista de la reforma puesta en marcha a partir de 1931. Constituye un medio de colaboración entre los inspectores, profesores y maestros, y es el exponente de las actividades educativas de la provincia, mostrando la realidad de sus problemas así como las instrucciones y posibles pautas para su mejor solución. Su contenido, en la medida que gira en torno a tres vértices fundamentales de la enseñanza primaria -escuela, normal, inspección-, proporciona una información útil sobre las relaciones del ecosistema que forman escuela y sociedad, sentando las bases de un coherente y ambicioso programa de renovación escolar.

En los testimonios de maestros e inspectores, hay que valorar la im-

60 Cita textual extraída del Informe personal correspondiente a D. Antolín Herrero Porras. Audio y 2 folios mecanografiados.

61 Boletín de Educación de León 5 (1934): 107.

62 Cita textual extraída del Informe personal correspondiente a D. José Muntada Bach, Audio y 18 folios mecanografiados. 
portancia de los indicios y datos acerca de la realidad del trabajo y de la organización escolar, así como de las funciones que cumplía la escuela: "Se preparaba la lección diariamente, con una disciplina persuasiva se buscaba instruir y educar, procurando que la escuela y las familias se conocieran y ayudaran en su misión" ${ }^{63}$. Por los textos vivos hemos podido conocer, a pesar de la precariedad de los edificios, la utilización en la escuela de un método activo, el planteamiento de una lección racional y eficaz donde el niño investiga y descubre, constatando la preparación diaria y anticipada de contenidos y medios por parte del maestro. Una organización de la escuela en la que alcanza notable significación el programa escolar influido por el principio de la Escuela Nueva. También hemos accedido a informaciones de carácter político-administrativo que incluyen la sensibilidad y efectos de disposiciones legislativas e información más específicamente pedagógicas como las relativas a programas y libros escolares, regímenes disciplinarios y académicos en la organización interna de las escuelas -excursiones, exposiciones escolares, fiestas-, mecanismos de formación continua de maestros y otras informaciones relacionadas con situaciones cotidianas de la vida escolar.

De otra parte, en el orden formativo, hay que destacar los datos suministrados sobre la nueva concepción y organización de las Normales, donde se pretendía formar a los nuevos maestros con un acentuado perfil profesional y pedagógico -métodos activos, mayor énfasis de las prácticas docentes- y acceder a relatos muy interesantes sobre iniciativas espectaculares como la implantación de gabinetes de paidología en las escuelas Normales. También se refleja la preocupación por la gestación y vicisitudes del nuevo sistema de selección de los maestros a través de cursillos y un claro apoyo y respaldo a los mecanismos impulsados para la formación y perfeccionamiento del profesorado en ejercicio a través de los Centros de Colaboración Pedagógica ${ }^{64}$ : "En el Centro trabajábamos maestros e inspectores los principales problemas de organización escolar y estudiába-

63 Cita textual extraída del Informe personal correspondiente a D. Alfonso Iniesta Corredor. Audio y 3 folios mecanografiados.

64 Boletín de Educación Nacional 8 (1934): 9-15; Boletín de Educación de León 3 (1933): 61-68; Boletín de Educación de Salamanca 6 (1934): 22-23. Archivo de La Inspección de Logroño. Libro de Actas del Consejo Provincial de Primera Enseñanza. Abierto el 5 de septiembre de 1931. Sesión de 
mos las nuevas corrientes pedagógicas imperantes en Europa, realizando una inestimable labor de difusión pedagógica" ${ }^{95}$.

Finalmente, en relación con la extensión educativa y la cultura popular, los testimonios aluden a la promoción de bibliotecas e instituciones circumescolares -cantinas, colonias, roperos-, al desarrollo de las Misiones Pedagógicas, a las campañas de alfabetización encomendadas a los maestros y a la proliferación de actividades de extensión y dinamización cultural ${ }^{66}$, muy próximos incluso a nuestras preocupaciones actuales, acreditándose sin discusión la existencia de un proceso de renovación pedagógica.

Estamos convencidos que la información y perspectivas que proporcionan los testimonios de los actores de la política educativa contribuyen a enriquecer las tesis más generales sobre el sentido y alcance de la reforma educativa republicana, mostrando el decisivo papel que protagonizaron los maestros e inspectores en el desarrollo y aplicación práctica de las innovaciones pedagógicas. Líneas de actuación que alcanzaron respaldo y reconocimiento internacional cuando la reforma republicana de la inspección figura expresamente valorada como movimiento de vanguardia y actuación ejemplificante en la publicación de la Oficina Internacional de Educación que en 1937 describe la inspección de enseñanza de treinta y nueve países ${ }^{67}$.

Llegados a este punto, tenemos la impresión de haber objetivado procesos renovadores a través de la voz y el recuerdo de los protagonistas de la educación, lo que nos permite mantener un optimismo pedagógico en torno

19 de abril de 1932. La Revista de Pedagogía informa de las actividades que llevan a cabo de manera conjunta inspecciones de diferentes provincias: “Organizada por la inspección de Burgos, Logroño y Álava se ha celebrado en Miranda de Ebro un curso de lecciones prácticas y de conferencias pedagógicas, al que han asistido más de 200 maestros”, Revista de Pedagogía 125 (1932): 239.

65 Cita textual extraída del Informe personal correspondiente a D. Adolfo Maíllo García. Audio y 7 folios mecanografiados.

66 Véase: Archivo de La Inspección Provincial de Educación de Córdoba. Libro de Actas de Sesiones del Consejo Provincial de Primera Enseñanza. Abierto con fecha de 1931.

67 Bureau International D'éducation (BIE), L’inspection de l'enseignement d'aprés les donnés fournies par les Ministères de L'Instruction Publique (Genève: BIE, 1937). 
a las posibilidades de la etnografía en la construcción de la historia de la política educativa. Percepción y sentimiento similar al que en 1935 expresa Alberto Malche, profesor de Pedagogía en la Universidad de Ginebra en su Prefacio a la interesante obra de Roberto Dottrens El problema de la inspección y la educación nueva ${ }^{68}$-publicada bajo los auspicios del Instituto J.J. Rousseau y de la Sociedad Belga de Paidotecnia y traducida por el inspector general de primera enseñanza Antonio Ballesteros y Usano-, cuando caracteriza a educadores e inspectores como sembradores del porvenir: "Una especie de fe les anima. Creen en la educación humana; ven en ella el más poderoso agente del progreso moral y social. Vuestros alumnos serán los directores hacia 1970, muchos verán el año 2000”.

\section{Consideraciones finales}

Bajo el estímulo de los cambios epistemológicos experimentados en las ciencias sociales, los historiadores se han visto obligados -al borde del acantilado ('au bord de la falaise') ${ }^{69}-$ a emprender nuevas reflexiones sobre la pertinencia de los objetos que construyen, sobre los métodos que utilizan y la forma en que escriben sus resultados.

En este contexto de reactivación epistemológica y metodológica, los intentos de dar voz y participación a los actores como el que aquí hemos presentado pueden contribuir a enriquecer sin duda los análisis más generales al permitir una mayor profundización en los aspectos que circulan entre los presupuestos político-administrativos de la educación y la práctica pedagógica, casi siempre resistentes a ser plasmados en la documentación impresa que genera una época. En este sentido, podemos asegurar que la historia oral y en general el recurso etnográfico muestra, tal vez mejor y de forma más convincente que otras posibles metodologías, las vicisitudes y niveles de realización de la política educativa, erigiéndose también en una de las vías privilegiadas para hacer inteligible y articular la praxis escolar.

68 Robert Dottrens, El problema de la inspección y la educación nueva (Prefacio de Alberto Malché, traducción y estudio sobre la organización escolar en España de Antonio Ballesteros y Usano), (Madrid: Espasa-Calpe, 1935).

69 Roger Chartier, Au bord de la falaise. L'histoire entre certitudes e inquiétudes (París: Albin Michel, 1997). 
No es exagerado afirmar que el acercamiento de la historia al sujeto y a la historia de los otros, en tanto que signos de la vida social, nos proporciona las claves para conocer el alcance real, efectos y grados de mitificación de las políticas educativas, los modos empíricos de producción del poder, así como las representaciones sociales y educativas en los que se materializan, la lógica de la acción colectiva y los cambios operados en el discurso pedagógico y en la práctica escolar.

Es demasiado arriesgado pensar que la historia de la política educativa responde a una función lineal. Por el contrario, al historiar el poder emergen certidumbres y acuerdos, también controversias e inquietudes en una trayectoria plagada de contrapuntos. Pero ante todo, quisiéramos atraer la atención hacia cómo en el seno de toda la fenomenología legal y administrativa que rezuma la creación, distintas reorganizaciones y expansión de los escenarios políticos, por encima incluso de las influencias y enfrentamientos de diferentes actitudes ideológicas, emerge la tesis central que sostiene la estrecha vinculación de las cuestiones del poder al sujeto que lo ejerce y, consecuentemente, a las percepciones y sentimientos de quienes lo vivencian. $\mathrm{Y}$ es, justamente, en esta perspectiva donde hemos puesto de manifiesto que la historia oral y el diseño etnográfico, debidamente sometidos a contraste y complementados con el recurso a fuentes impresas con las que resultan lógicamente compatibles, aportan una aproximación creativa, imprescindible para interpretar la dialéctica y contradicciones que exhibe la política y en nuestro estudio el propio desarrollo de la reforma educativa republicana. En este sentido, hemos querido mostrar cómo el diseño etnográfico, cuando es posible, también ayuda a problematizar la historia, se erige como método eficaz y produce nuevos resultados.

\section{Bibliografía}

Fuentes primarias. Documentos inéditos de archivo Archivo Histórico Provincial de Burgos

Libro de Actas de Sesiones del Ayuntamiento de Burgos. Sesión de 12 de julio de 1933. 
Libro de Actas de Sesiones del Consejo Local de Primera Enseñanza de Castañares. Abierto en 1931.

\section{Archivo de la Inspección Provincial de Educación de Logroño}

Libro de Actas del Consejo Provincial de Primera Enseñanza. Abierto en 1931.

\section{Archivo de la Inspección Provincial de Educación de Córdoba}

Libro de Actas del Consejo Provincial de Primera Enseñanza. Abierto con fecha de 1931.

\section{Libros de Visita de Inspección}

Libro de Visitas de Inspección de la Escuela de Alesón (La Rioja). Abierto en 1930.

Libro de Visitas de Inspección de la Escuela de Alba de Tormes (Salamanca). Abierto en 1865.

Libro de Visitas de Inspección de la Escuela de Barceíno (Salamanca). Abierto en 1871.

Libro de Visitas de Inspección de la Escuela de Campo de Ledesma (Salamanca). Abierto en 1861.

Libro de Visitas de Inspección de la Escuela de Cantalapiedra (Salamanca). Abierto en 1878.

Libro de Visitas de Inspección de la Escuela de Guadramiro (Salamanca). Abierto en 1860.

Libro de Visitas de Inspección de la Escuela de Herce (La Rioja). Abierto en 1935.

Libro de Visitas de Inspección de la Escuela de Medina del Campo (Valladolid). Abierto en 1934.

Libro de visitas de Inspección de la Escuela de Mota del Marqués (Valladolid). Abierto en 1932.

Libro de Visitas de Inspección de la Escuela de Peralejos de Abajo (Salamanca). Abierto en 1860.

Libro de Visitas de Inspección de la Escuela de Rodilana (Valladolid). Abierto en 1935.

Informes y testimonios de maestros e inspectores en activo durante el período republicano

248 D a Salvadora Devesa Cano. Audio y 2 folios mecanografiados. Alicante, 4 de diciembre de 1980.

Da Francisca González Rivero. Audio y 9 cuartillas manuscritas. Santan- 
der, 21 de septiembre de 1980.

D. Antolín Herrero Porras. Audio y 2 folios mecanografiados. Logroño, 20 de mayo de 1983.

D. Alfonso Iniesta Corredor. Audio y 3 folios mecanografiados. Madrid, 14 de mayo de 1981.

D. Adolfo Maíllo García. Audio y 7 folios mecanografiados. Salamanca, 21 de febrero de 1980.

D. Alejandro Manzanares Beriaín. Audio y 7 folios mecanografiados. Logroño, 19 de octubre de 1982.

D. Luis María Mestras. Audio y 6 folios mecanografiados. Gerona, 14 de abril de 1982.

D. José Muntada Bach. Audio y 18 folios mecanografiados. Barcelona, 3 de marzo de 1982.

D. Cipriano Pinés Espadas. Audio y 2 folios mecanografiados. Madrid, 4 de mayo de 1980.

D. Ubaldo Ruiz Tablado. Audio y 2 cuartillas manuscritas. Ávila, 17 de mayo de 1981.

Publicaciones periódicas. Prensa profesional y pedagógica de difusión nacional (1931-1936)

Diarios: El Debate, El Socialista, El Sol.

Prensa pedagógica: Boletín de la Institución Libre de Enseñanza, El Magisterio Español, Revista de Escuelas Normales, Revista de Pedagogía.

Boletines de Educación (se indica el año inicial de publicación): Boletín de Educación Nacional (1933). Boletines Provinciales: Alicante (1933), León (1933), Logroño (1934), Málaga (1934), Navarra (1935), Palencia (1933), Salamanca (1934), Toledo (1935), Zaragoza (1936)

\section{Fuentes secundarias}

Aceves, Jorge Eduardo. "La historia oral y de vida: del recurso técnico a la experiencia de investigación". En Técnicas de investigación en sociedad, cultura y comunicación, editado por Luis Jesús Galindo. México: Pearson, 1998, 207-276.

Alcalá-Zamora, Niceto. Los defectos de la Constitución de 1931. Madrid: Espinosa, 1936.

Álvarez, Rafael, Juan Comas y Juvenal de Vega. Manual del inspector de 
Primera Enseñanza. Madrid: Publicaciones de la Revista de Pedagogía, 1934.

Arrarás, Joaquín. Historia de la Segunda República española. I. Madrid: Editora Nacional, 1956.

Bello, Luis. I. El cerco de Madrid; viaje a la sierra por Castilla y León; Asturias; el prejuicio contra el maestro; la Sociedad de Amigos de la Escuela - II. Por Andalucía: Cádiz, Málaga, Granada; Las dos Castillas: Toledo, Soria - III. Extremadura: suma de varios viajes, Cáceres y Badajoz, cien kilómetros en Portugal - IV. Más Andalucía: las siete Huelvas, Sevilla: viaje preliminar; viaje de instrucción a Tánger; Jaén: viaje a Santiago de la Espada. Madrid: Magisterio Español, 19261929.

Bentley, Arthur Fisher. The Process of Government. A Study of Social Pressures. Chicago: University of Chicago Press, 1908.

Bertaux, Daniel. Los relatos de vida. Perspectiva etnosociológica. Barcelona: Ediciones Bellaterra, 2005.

Biernacki, Patrick y Dan Waldorf . "Snowball sampling: Problemas and techniques of cain referral sampling". Sociological Methods and Research 10 (1981): 141-163.

Bloch, Marc Léopold Benjamin. Introducción a la historia. México: FCE, 1985.

Bureau International D'Éducation (BIE). L'inspection de l'enseignement d'aprés les donnés fournies par les Ministères de L'Instruction Publique. Genève: BIE, 1937.

Cabral Pinto, Fernando (Coord.). Educaçao, História e Políticas. Tributo a Rogério Eernandes. Lisboa: Ediçôes Piaget, 2015.

Carreras, Juan José "El marco internacional de la II República". Arbor 426-427 (1981): 37-50.

Chartier, Roger. Au bord de la falaise. L'histoire entre certitudes e inquiétudes. París: Albin Michel, 1997.

Cos Gayón, Fernando. Historia de la Administración Pública en España. Madrid: Escuela Nacional de Administración Pública, 1976.

Crook, David y Richard Aldrich. History of Education for the Twenty-First Century. London: Institute of Education, 2000.

250 Depaepe, Marc. L'apport de l'histoire de l'éducation a la définition des politiques éducatives. Quelques réflexions méthodologiques. En L'offre de l'école. París: Publications de la Sorbonne-INRP, 1983. 
Diaz de Arcaya, F. La reforma agraria de 15 de septiembre de 1932. Comentada con su doctrina parlamentaria y disposiciones complementarias. Madrid: Reus, 1935.

Domingo, Marcelino. Le escuela en la República (La obra de ocho meses). Madrid: M. Aguilar, 1932.

Dottrens, Robert. El problema de la inspección y la educación nueva (Prefacio de Alberto Malche, traducción y estudio sobre la organización escolar en España de Antonio Ballesteros y Usano). Madrid: Espasa-Calpe, 1935.

Easton, David. A framework for political analysis. New Jersey: Prentice-Hall, 1965.

Eco, Umberto. Prólogo a J. Lozano. El discurso histórico, Madrid: Alianza Editorial, 1994.

Escolano, Agustín. “Introducción”, En Diccionario de Ciencias de la Educación. Tomo de Historia de la Educación I. Madrid: Anaya, 1984, IX-XLIII.

Escolano, Agustín. "Introducción” en El niño republicano, editado por Joaquín Seró Sabaté. Madrid: Edaf, 2000.

Escolano, Agustín: "Ethnohistory of the School. Representations of Modernity". Sisyphus. Journal of Education 4,1 (2016): 12-41.

Escolano, Agustín y Rogério Fernández (Eds.). Los caminos hacia la modernidad educativa en España y Portugal (1800-1975). Zamora: SEDHE, Fundación Rei Afonso Henriques, 1997.

Escolano, Agustín y Jose María Hernández (Coords.). La memoria y el deseo. Cultura de la escuela y educación deseada. Valencia: Tirant lo Blanc, 2002.

Espín Templado, Eduardo. "El panorama militar". Revista de Occidente 7-8 (1981): 39-57.

Febvre, Lucien. Combates por la Historia. Barcelona: Ariel, 1974.

Fernández-Carvajal, Rodrigo. El lugar de la ciencia política. Murcia: Universidad de Murcia, 1981.

Fernández Soria, Juan Manuel. "La nueva historia política de la educación”. Historia de la Educación 25 (2006):71-103.

Ferraz, Manuel (Ed.). Repensar la historia de la Educación. Nuevos desafíos, nuevas propuestas. Madrid: Biblioteca Nueva, 2006.

Flora, Peter and Arnold Heidenheimer (Eds). The development of wel- 
fare state in Europe and in America. New Brunswick: Transaction Books, 1981.

Folguera, Pilar. Cómo se hace historia oral. Madrid: Eudema,1994.

Foucault, Michel. L'Ordre du discours. Leçon inaugurale au Collège de

France prononcée le 2 décembre. París: Gallimard, 1970. (Traducción: El orden del discurso. Barcelona: Tusquets, 1987).

García Colmenares, Carmen y Luz Martínez Ten. La escuela de la Repúbli-

ca. Memoria de una ilusión. Madrid: FETE-UGT, La Catarata, 2014.

Guereña, Jean Louis, Julio Ruiz Berrio y Alejandro Tiana Ferrer (Eds.).

Historia de la educación en la España contemporánea. Diez años de investigación. Madrid: CIDE, 1994.

Jiménez Eguizábal, Alfredo. La Inspección de Primera Enseñanza en la Segunda República Española. Salamanca: Universidad de Salamanca, 1984.

Jiménez Eguizábal, Alfredo. "Evolución institucional de la Escuela de Estudios Superiores del Magisterio. Objetivos y contenidos a través de los planes de estudio". En Escuela de Estudios Superiores del Magisterio (1909-1932). Un precedente histórico en la Formación Universitaria del Profesorado Español, editado por Antonio Molero Pintado y María del Mar del Pozo Andrés. Madrid: Universidad de Alcalá, 1989.

Le Goff, Jacques y Pierre Nora. Hacer la historia. I. Nuevos problemas, II. Nuevos enfoques, III. Nuevos temas. Barcelona: Laia, 1978-1980. Lozano Seijas, Claudio. La educación republicana. Barcelona: Universidad de Barcelona, 1980.

LLopis Roberto. La revolución en la escuela. Dos años en la Dirección general de Primera enseñanza. Madrid: M. Aguilar, 1933.

Mayordomo, Alejandro. Perspectivas de la política educativa española. Valencia: Universidad de Valencia, 1985.

Molero Pintado, Antonio. La reforma educativa de la Segunda República Española. Madrid: Edicusa, 1975.

Molero Pintado, Antonio. Historia de la Educación en España, Vol IV, La educación durante la Segunda República y la Guerra Civil (19311939). Madrid: MEC, 1991.

Morant, Isabel. "Introducción”. En Escribir las prácticas: discurso, práctica, representación, editado por Roger Chartier. Valencia: Fundación 


\section{Cañada Blanch, 1999.}

Moreno, Pedro Luis y Antonio Viñao. Imagen y educación: marketing, comercialización y didáctica. España: Siglo XX. Madrid: Morata, 2017. Mori, Arturo. Crónica de las Cortes Constituyentes de la II República Española. Madrid: M. Aguilar, 1932.

Nóvoa, Antonio. "La nouvelle histoire américain de l'éducation" Histoire de l'éducation 73 (1997).

Nóvoa, Antonio y Julio Ruiz Berrio (Eds.). A História da Educaçao em Espanha e Portugal. Investigaçoes e atividades. Lisboa: Sociedade Portuguesa de Ciências da Educaçao-Sociedad Española de Historia de la Educación, 1993.

Palmero Cámara, Carmen. Educación y Sociedad en La Rioja Republicana (1931-1936). Salamanca-Logroño: Universidad Pontificia de Salamanca-Gobierno de La Rioja, IER, 1990.

Palmero Cámara, Carmen. La Escuela Republicana en Burgos. En La Escuela Primaria en Castilla y León, coordinada por José María Hernández Díaz. Salamanca: Amarú Ediciones, 1993, 139-158.

Pérez Galán, Mariano. La enseñanza en la Segunda República Española. Madrid: Edicusa, 1975.

Pozo Andrés, María del Mar del. "Imágenes e historia de la educación: construcción, reconstrucción y representación de las prácticas escolares en el aula", Historia de la Educación, 25 (2006): 291-315.

Porto, Ángel Serafín y Raquel Vázquez. La escuela activa y el entorno. Una aproximación a través de los paseos, visitas y excursiones durante la Segunda República. Santiago de Compostela: Andavira, 2017.

Puelles Benítez, Manuel de. "Política de la educación. Viejos y nuevos campos de conocimientos". Revista de Ciencias de la Educación 178-179 (1999): 187-206.

Puelles Benítez, Manuel de. Política educativa en perspectiva histórica. Madrid: Biblioteca Nueva, 2017.

Ruiz Berrio, Julio. "El método histórico en la investigación histórico-educativa”. En La investigación histórico-educativa, editado por Narciso de Gabriel y Antonio Viñao. Barcelona: Ronsel, 1997, 131-202.

Ruiz Berrio, Julio (ed.). La cultura escolar de Europa. Tendencias históricas emergentes. Madrid: Biblioteca Nueva, 2000.

Salimova, Kadriya and Erwin V. Johanningmeir (Eds.). Why should we teach history of education? Moscow: The Library of International Academy of Self-Improvement, 1993. 
Samaniego Boneu, Mercedes. La política educativa de la Segunda República durante el bienio azañista. Madrid: CSIC, 1977.

Scribner, Jay D. and Donald H. Layton (Eds.). The study of educational politics. Washington-London: The Falmer Press, 1995.

Shopes, Linda. "Diseño de proyectos de historia oral y formas de entrevistar". Revista Historia y Fuente Oral, 25 (2001): 133-141.

Skocpol, Theda. "Bringing the State back in: strategies of analysis in current research". En Bringing the State Back In. editado por Peter Evans, Dietrich Rueschemeyer y Theda Skocpol. Cambridge: Cambridge University Press, 1985.

Vicens Vives, Jaime. Historia social y económica de España y de América. Barcelona: Vicens Vives, 1977, 350-383.

Vidal i Barraquer, Arxiu Esglesia i Estat durant la Segona República Espanyola (1931-1936). Edición presentada y comentada por Miquel Batllori y Victor Manuel Arbeloa. Barcelona: Abadía de Montserrat, 1971-1977.

Viñao, Antonio. Política y educación en los orígenes de la España contemporánea. Examen especial de sus relaciones en la enseñanza secundaria. Madrid: Siglo XXI, 1982.

Viñao, Antonio. "La memoria escolar: restos y huellas, recuerdos y olvidos". Annali si Storia dell'Educazione e dell Istittuzione Scholastiche 12 (2005): 19-33.

Yanes-Cabrera, Cristina, Juri Meda y Antonio Viñao (Eds.). School Memories. New Trends in the History of Education. Switzerland: Springer International Publishing, 2016.

Para citar este artículo: Jiménez Eguizábal, Juan Alfredo y Palmero Cá-

mara, Carmen. "Etnohistoria y política educativa. Repensando el sujeto y las fuentes en la reforma educativa republicana en España (1931-1936)", Vol. XIII No. 33 (Julio-Diciembre 2018): 217-252. DOI: http://dx.doi. org/10.15648/hc.33.2018.9 